adding a renin-depressing agent. The range where the pressure effect of the two drugs was uncorrelated to the PRA-levels $\left(1 \cdot 0-2 \cdot 0: \mathrm{g} \mathrm{AI} 1^{-1} \mathrm{~h}^{-1}\right)$ might represent the normal range of PRA.

We conclude from this controlled investigation with propranolol and spironolactone in primary hypertension that both drugs have valuable antihypertensive properties, but their combination results in a further reduction in blood pressure. Our findings also support the concept that patients with high renin concentrations respond more favourably to beta-blocking agents - that is, propranolol - and that those with low renin concentrations respond better to spironolactone. The data also suggest that the renin-angiotensin-aldosterone system may be implicated in primary hypertension.

We thank Mr Bo Bergman for skillful and painstaking statistical aid and Miss Inger Larsson for performing the PRA-determinations.

Propranolol (Inderal), and propranolol placebo tablets were supplied by ICI Pharma AB, Gothenburg, and spironolactone (Aldactone) and spironolactone placebo tablets by G D Searle AB, Malmö, Sweden.

\author{
References \\ ${ }^{1}$ Laragh, J H, American fournal of Medicine, 1973, 55, 261. \\ 2 Brunner, H R, et al, New England fournal of Medicine, 1972, 286, 441. \\ 3 Bühler, F R, et al, New England fournal of Medicine, 1972, 287, 1209. \\ ${ }^{4}$ Morgan, T O, et al, British fournal of Clinical Pharmacology, 1975, 2, 159. \\ ${ }^{5}$ Crane, M G, and Harris, J J, American fournal of Medical Science, 1970, \\ 260, 311 . \\ ${ }^{6}$ Carey, R M, et al, Archives of Internal Medicine, 1972, 130, 849.
}

'Vaughan, E D, et al, American fournal of Cardiology, 1973, 32, 523.

${ }^{8}$ Haber, E, et al, fournal of Clinical Endocrinology, and Metabolism, 1969, 29, 1349.

${ }^{9}$ Gitelman, H J, Analytical Biochemistry, 1967, 18, 520.

${ }^{10}$ Marsh, W H, Fingerhut, B, and Miller, H, Clinical Chemistry, 1965, 11, 624.

${ }^{11}$ McKenzie, J K, and Clements, J A, fournal of Clinical Endocrinology and Metabolism, 1974, 38, 622.

12 Hajek, J, A Course in Nonparametric Statistics. San Francisco, Holden-Day, 1969.

${ }^{13}$ Rao, C R, Linear Statistical Inference and its Applications, p 199. New York, Wiley, 1965.

14 Tuck, M L, et al, American fournal of Cardiology, 1973, 32, 637.

15 Sambhi, M P, Crane, M G, and Genest, J, Annals of Internal Medicine, 1973, 79, 411.

${ }^{16}$ Swales, J D, Lancet, 1975, 1, 75.

17 Paterson, J W, and Dollery, C T, Lancet, 1966, 2, 1148.

${ }_{18}$ Humphreys, G S, and Delvin, D G, British Medical fournal, 1968, 2, 601.

19 Hansson, L, et al, International fournal of Clinical Pharmacology, 1974, $10,79$.

${ }^{20}$ Ogilvie, R I, and Ruedy, J, Canadian Medical Association fournal, 1969, 101,61 .

21 Adlin, E V, Marks, A D, and Channick, B J, Archives of Internal Medicine, 1972, 130, 855.

${ }^{22}$ Ferries, J B, et al, British Medical fournal, 1975, 1, 135.

${ }^{23}$ Dunn, M J, and Tannen, R L, Kidney International, 1974, 5, 317.

24 Oparil, S, and Haber, E, New England fournal of Medicine, 1974, 291, 389.

${ }_{25}$ Michelakis, A M, and McAllister, R G, Fournal of Clinical Endocrinology and Metabolism, 1972, 34, 386.

${ }^{26}$ Hansson, L, and Zweifler, A J, Acta Medica Scandinavica, 1974, 195, 397.

27 Leonetti, G, et al, Clinical Science and Molecular Medicine, 1975, 48, 491.

${ }^{28}$ Hunyor, S N, et al, Australian and New Zealand Fournal of Medicine, 1975, 5,17 .

29 Spark, R F, O'Hara, C M, and Regan, R M, Archives of Internal Medicine, 1974, 133, 205.

\title{
Support for varicose veins
}

\author{
P H FENTEM, MARILYN GODDARD, B A GOODEN
}

British Medical fournal, 1976, 1, 254-256

\section{Summary}

A method has been devised to allow reliable comparison of different strengths and constructions of support hosiery. Five garments were evaluated for the compression they exerted on the leg and their ability to limit the distension of a model varicose vein. Stockings and tights which provide modest compression can achieve worthwhile control of vein distension.

\section{Introduction}

The comfort given by support hosiery, and any possible therapeutic effect on varicose veins is related to the pressure exerted on the legs. ${ }^{1}$ A variety of garments is available, ranging from heavyweight elastic stockings to cosmetically acceptable nylon and elastane hosiery. This study measures the support given by different types of hosiery. Few studies of compression have been undertaken either by manufacturers concerned with establishing the correct design and strength of hosiery ${ }^{2}$ or in the course of clinical studies where it was necessary to describe a particular garment. Meyerowitz and Crook $^{3}$ used a small, airfilled bag to measure, at calf level, the compression provided by one-way stretch elastic stockings. Makin et $a l^{4}$ measured the

Department of Physiology \& Pharmacology, Medical School, University of Nottingham, Nottingham NG7 2 UH

P H FENTEM, MSC, MB, professor of physiology

MARILYN GODDARD, BSC, research assistant

B A GOODEN, MD, lecturer in physiology

pressure exerted on the calf by knee-high Tubigrip elastic stockings using a large polyethylene bag containing saline.

Consideration of the efficacy of different support garments suggested that we needed to study not only the compression exerted on the leg but also the ability of the hosiery to limit the distension of varicose veins. The pressure which a garment exerts on the leg will depend on both its tension and the radius of the limb at a given level. The tension depends on the elasticity of the material and the way it is made. The Laplace relationship states that compression $(\mathbf{P})$ is inversely proportional to radius (R) for a constant rension ( $T)(P=T / R)$. Thus, a decrease in the radius over which the tension of the garment is acting will give an increase in compression. It follows that the compression exerted by hosiery on a distended varicose vein, with a radius of curvature much smaller than that of the whole limb, will be proportionately greater than the compression exerted on the limb at that level. The effect of this compression may be deduced from an examination of the pressure-volume relationship of a varicose vein when it is supported by hosiery, and from measurements of the reduction in volume of blood which collects in varicose veins when they are supported by hosiery and exposed to various distending pressures.

Two methods of measuring support were devised: firstly, compression was measured by a large, flat, liquid-filled bag; secondly, a model varicose vein was constructed so that an estimate of the pressure-volume relationship of a distended superficial vein under hosiery could be made without the difficulties associated with measuring a real vein.

\section{Materials and methods}

Five types of two-way stretch garments were selected for the tests: (a) 250-denier, nylon-covered, elastane support tights; (b) nyloncovered, 0.3-mm rubber core, National Health stockings; (c) 115denier, nylon-covered elastane support stockings; (d) 115-denier, 
nylon-covered, elastane support tights (construction different from (c)); (e) 20-denier non-supporting tights.

Six healthy women were invited to take part in the study and wear each type of garment. The subjects were aged 18-45 (mean 25), with heights ranging from 1.55-1.68 metres, and calf circumferences of $320-370 \mathrm{~mm}$. None of the women had visible varicose veins. A new garment was used for each woman and the manufacturers' fitting instructions were followed. Stockings were firmly suspended at three positions on the thigh welt. The subjects rested horizontally on a couch during the experiments. Each garment was tested twice on each woman within one hour of fitting. Garment $c$ was deliberately used two sizes larger and two sizes smaller than the correct fitting.

Measuring compression exerted by hosiery - It has been shown that a large, fairly inelastic bag containing a small quantity of incompressible fluid can accurately detect pressure applied to its surface. ${ }^{4}$ Such a device moulds readily to the leg contours and causes no significant increase in the radius of the leg. The compression exerted by the hosiery was measured using a $100 \times 80-\mathrm{mm}$ bag made from polyvinylchloride, $0.25 \mathrm{~mm}$ thick, connected by nylon tubing (internal diameter $1 \mathrm{~mm}$ ) to a Bell and Howell L221 pressure transducer, and thence to an ultraviolet recording device (SE 3006). The measurements were made with $5 \mathrm{ml}$ of water in the bag. Preliminary experiments showed that when the bag held between $3 \mathrm{ml}$ and $8 \mathrm{ml}$ of water it could accurately detect radial pressure. The bag was secured to the anterior surface of the leg at the ankle, calf, and thigh. A pressure reading was taken. The garment was drawn over the bag and fitted on to the leg, and a second reading was taken. The difference between the two measurements was noted as the pressure exerted by the hosiery on the leg.

Pressure-volume relationship of a varicose vein model-A varicose vein model was made from a $150-\mathrm{mm}$ length of Viskin nylon tubing, volume $28 \mathrm{ml}$, diameter $15 \mathrm{~mm}$, and thickness $0.4 \mathrm{~mm}$, sealed on to polythene tubing, internal diameter $2.2 \mathrm{~mm}$. The tubing within the model was perforated to facilitate free distribution of water during filling. The pressure inside the model was measured and recorded as described previously. Fluid could be infused into the model at a rate of $8 \mathrm{ml} / \mathrm{min}$ by means of a syringe located between the model and the pressure transducer, using an infusion pump (Sage 351). The collapsed model was secured to the leg with adhesive tape in the positions previously described, the pressure and volume being noted. Water was infused into the model and a control pressure-volume curve was obtained. The garment was applied and a second pressure-volume curve was recorded. The effect of hosiery size on this measurement was investigated. The pressure-volume curves obtained using incorrectly fitted garment $c$ were compared with results from the correctly fitted stocking.

Analysis of data-The effect of hosiery application on the pressurevolume relationship of the vein model was expressed as:

$$
\text { volume of model with hosiery }
$$

of model without hosiery

at a given pressure. This ratio described the volume of fluid that had to be infused to raise the pressure of the model to a particular level, expressed as a percentage of the model volume when no garment was worn. Firstly, this ratio was calculated for a pressure of $40 \mathrm{~mm} \mathrm{Hg}$ $(5.3 \mathrm{kPa})$, and, secondly, for the pressure corresponding to the hydrostatic pressure distending the vein at the site of measurement for an upright and motionless subject, assuming a continuous column of blood to the level of the heart.

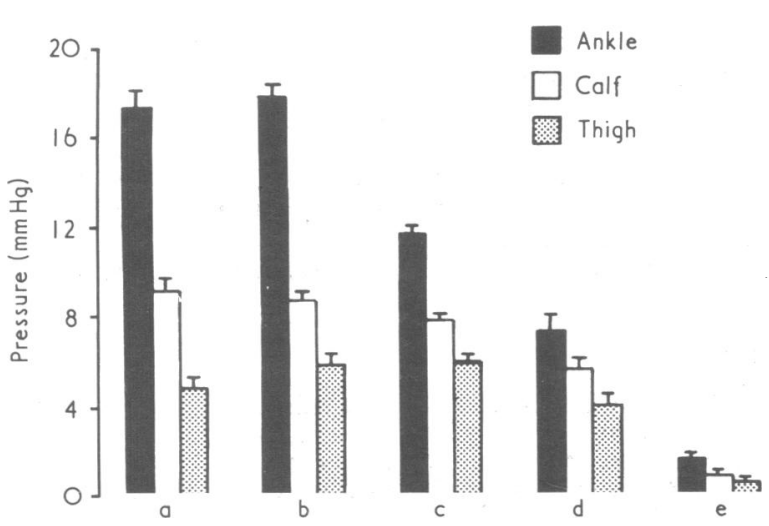

FIG $1-$ Mean compression ( $\pm 1 \mathrm{SE}$ ) exerted by five garments, $a-e$, at ankle, calf, and thigh in six women.

\section{Results}

\section{COMPRESSION EXERTED BY HOSIERY}

All types of support garment showed a gradation of compression which increased from thigh to ankle (fig 1). Compression values ranged from a maximum of $17.6 \mathrm{~mm} \mathrm{Hg}(2.3 \mathrm{kPa}) \pm 0.6$ for the heavyweight garment $a$, to $0.5 \mathrm{~mm} \mathrm{Hg}(0.06 \mathrm{kPa}) \pm 0.25$ for nonsupporting hosiery $e$.

PRESSURE-VOLUME RELATIONSHIP OF VARICOSE VEIN MODEL

Fig 2 shows the shape of the filling curve for the vein model without hosiery, and the pressure-volume relationship of the model under garment $d$ at calf level. Volume is expressed as a percentage of the volume of the unsupported model at $100 \mathrm{~mm} \mathrm{Hg}(13.3 \mathrm{kPa})$. Infusion of fluid into the model vein caused the pressure to rise much more rapidly when the model was under a support garment. For any given distending pressure up to $100 \mathrm{~mm} \mathrm{Hg}(13.3 \mathrm{kPa})$ these garments reduced the volume of fluid in the model vein. The shape of the pressurevolume curve obtained for the different garments was similar but not identical.

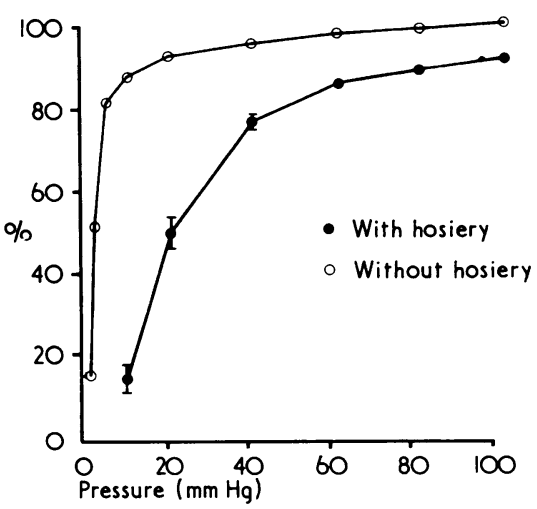

FIG 2-Pressure-volume relationship of vein model at calf level. Mean volume expressed as percentage of control volume at $100 \mathrm{~mm} \mathrm{Hg}(13.3 \mathrm{kPa})$ $( \pm 1 \mathrm{SE})$ in six women. When none is shown SE was less than $1 \%$.

TABLE I-Mean $( \pm 1 S E)$ volume of fluid (expressed as percentage of vein model volume without hosiery) that had to be infused to raise pressure of model to values corresponding to hydrostatic pressure distending a vein at level of measurement in six women

\begin{tabular}{c|c|c|c}
\hline Hosiery & Ankle & Calf & Thigh \\
\hline$a$ & $70.4 \pm 5.0$ & $78.5 \pm 3.0$ & $95.4 \pm 1.4$ \\
$b$ & $71.5 \pm 3.2$ & $78.2 \pm 1.3$ & $81.5 \pm 2.3$ \\
$c$ & $76.9 \pm 1.3$ & $84.8 \pm 1.9$ & $86.3 \pm 1.9$ \\
$d$ & $85.2 \pm 3.3$ & $90.5 \pm 1.2$ & $94.4 \pm 1.2$ \\
$e$ & $99.15 \pm 0.2$ & $99.4 \pm 0.3$ & $99.8 \pm 0.1$ \\
\hline
\end{tabular}

Reduction of the model volume observed at $40 \mathrm{~mm} \mathrm{Hg}(5.3 \mathrm{kPa})$ under the five garments is shown in fig 3 . The gradient effect was shown again, with maximum volume reduction at the ankle. When the measurements were made by the two techniques in the same place on the leg, there was a significant linear relationship between the compression exerted by hosiery on the leg and the effect of this compression on the pressure-volume relationship of the model $(r=0.97 ; P<0.001)$.

Reduction of model volume produced by these garments at pressures corresponding to the hydrostatic pressure distending a vein at the site of measurement was expressed as a percentage of the volume of the unsupported model at these pressures (table I). Comparison of the filling curves for the supported and unsupported model at calf level showed that reduction in the volume of the model by hosiery was less as the pressure increased (fig 2 ). The model volume was reduced by $20 \%$ at $40 \mathrm{~mm} \mathrm{Hg}(5.3 \mathrm{kPa})$ pressure, and only $10 \%$ at $80 \mathrm{~mm} \mathrm{Hg}$ $(10.6 \mathrm{kPa})$. The hosiery, however, had a gradation of compression which increased towards the ankle and so at ankle level, where there was a large hydrostatic component, support was greater. The overall effect was a reduction in model volume at all levels of the leg with maximum support at the ankle, followed by calf and then thigh. 


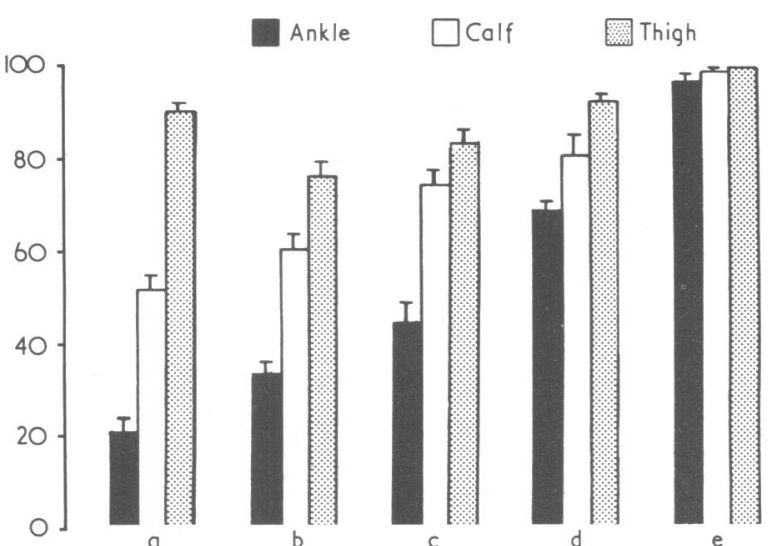

FIG 3-Mean ( \pm SE) volume of fluid expressed as percentage of volume of vein model without hosiery required to be infused to raise pressure of model to $40 \mathrm{~mm} \mathrm{Hg}(5 \cdot 3 \mathrm{kPa})$ when supported by five garments, $a-e$. Four women were studied.

TABLE II-Effect of hosiery size on reduction in volume of vein model at $5 \cdot 3 \mathrm{kPa}$ $(40 \mathrm{~mm} \mathrm{Hg}$ ) (results expressed as mean ( $\pm 1 S E$ ) percentage of model volume when no garment was worn) and mean $( \pm 1 S E)$ compression exerted by incorrectly fitted hosiery at ankle, calf, and thigh on six women

\begin{tabular}{|c|c|c|c|}
\hline Garment $c$ size & Ankle & Calf & Thigh \\
\hline \multicolumn{4}{|c|}{ Effect of hosiery size on reduction in volume of model } \\
\hline $\begin{array}{l}\text { Too small } \\
\text { Correct } \\
\text { Too large }\end{array}$ & $\begin{array}{l}63.2 \pm 1.4 \\
55.6 \pm 4.35 \\
52.5 \pm 4.5\end{array}$ & $\begin{array}{ll}29 \cdot 3 & \pm 4 \cdot 5 \\
27.2 & \pm 2 \cdot 8 \\
25.6 & \pm 2.3\end{array}$ & $\begin{array}{l}19.4 \pm 6.3 \\
17.6 \pm 3.1 \\
14.4 \pm 1.6\end{array}$ \\
\hline \multicolumn{4}{|c|}{ Compression exerted by incorrectly fitted hosiery $(\mathrm{mm} \mathrm{Hg})$} \\
\hline $\begin{array}{l}\text { Too small } \\
\text { Correct } \\
\text { Too large }\end{array}$ & $\begin{array}{l}10.6 \pm 0.9 \\
11.16 \pm 0.3 \\
8.3 \pm 0.75\end{array}$ & $\begin{array}{l}7 \cdot 4 \pm 0.4 \\
7 \cdot 14 \pm 0 \cdot 6 \\
6 \cdot 2 \pm 0.4\end{array}$ & $\begin{array}{l}5.4 \pm 0.4 \\
5.4 \pm 0.2 \\
5.6 \pm 0.3\end{array}$ \\
\hline
\end{tabular}

The pressure-volume relationship of the model under incorrectly fitted nylon and elastane hosiery did not differ significantly from results obtained for the correct size (table II). The compression values for this test were shown to be similar for the small, correct, and large fitting (table II).

\section{Discussion}

The efficacy of different strengths and constructions of support hosiery may be reliably compared using two simple measurements. It is possible to measure compression exerted on the leg surface by hosiery and the ability of the garment to limit the distension of a model vein. Since one aim of support hosiery is to control the distension of varicose veins it seems logical to include measurements of this property in the physical assessment of these garments and to carry out this measurement on the leg.

A large bag containing only a small volume of liquid must be used in measuring compression. Fluid-filled tubes or balloons of a calibre similar to a superficial vein are unsuitable for measuring the overall compression exerted on the leg. We have already referred to the importance of the physical principle whereby the radius of curvature of a balloon or tube determines the pressure which is recorded within it when it is under a covering stretched to a particular tension. It is possibly significant that high values for compression by hosiery have been described in studies in which small balloons have been used to make the measurement. Somerville et $a^{5}$ recorded values of $90 \mathrm{~mm} \mathrm{Hg}$ $(11.0 \mathrm{kPa})$ for elastic stockings when using a small rubber bulb to measure compression. They probably over-estimated this pressure since these are values which would be expected to impede arterial inflow to the $\operatorname{limb}^{6}$ and no such effect was described.

Nevertheless, study of the pressure-volume relationships of small tubes is informative. A distended varicose vein under hosiery presents a surface which has a small radius of curvature when compared with the radius of the whole leg. Because of this the pressure on the vein is much greater than the pressure applied to the limb (the Laplace relationship). The data in fig 2 can be used to illustrate this point. Garment $d$ exerted a compression of $6 \mathrm{~mm} \mathrm{Hg}(0.8 \mathrm{kPa})$ around the calf. Fig 2 shows that the measured pressure within the model vein at $90 \%$ distension under this garment at calf level was greater than $90 \mathrm{~mm} \mathrm{Hg}(10.6$ $\mathrm{kPa}$ ), which supports this hypothesis. Thus a leg vein will assume an elliptical cross-section with a maximum radius such that the external compression force of the garment is balanced by the internal distending pressure of the vein. In this way the distension of varicose veins will be controlled.

Experiments were carried out to determine the effect of the structure of the vein model on the pressure-volume relationship of the model under hosiery. The results obtained using segments of long saphenous varicose veins were very similar to those obtained using the vein model. These and other investigations into the effect of model diameter and the effect obtained when the vein model overlies bone or soft tissue will be described elsewhere.

All the support garments examined produced gradations of compression which increased from thigh towards the ankle, a principle which is physiologically sound. The hydrostatic component distending a varicose vein at any level will be greater towards the ankle for a standing person, and thus the support needed lower in the leg will be greater. The garments are tailored to the leg contours so that the circumference of the hosiery increases towards the thigh and tension in the fibres is relatively constant along the length of the leg, but since the leg radius decreases towards the ankle the pressure will increase (Laplace relationship).

Incorrectly fitted nylon and elastane hosiery $c$ did not exert significantly different pressures on the leg when compared with values obtained for the correct size. Compression values on the leg are unchanged so long as the garment is stretched within its elastic limits, and since elastane fibres are highly extensible there is a large working range. The final extensibility of the garment is determined by its construction and the proportion of elastane fibres contained in it. Hosiery constructed entirely from nylon is less able to stretch freely over different leg sizes since nylon has a high Young's modulus of extensibility. Compression values recorded will depend to some extent on the correct fitting of hosiery. Movements of the leg while walking, however, will result in pressure fluctuations as the tension changes, and thus slight variations in measurements recorded from the resting leg are considered to be negligible.

Previous studies have been concerned with the measurement of compression exerted by hosiery on the whole leg and the assumption is easily made that these are the forces acting on a superficial varicose vein. Measurements of the pressure-volume characteristics of a model vein supported by hosiery confirm the hypothesis that the forces acting on the vein are determined by the size of the vein and its position. Although the compression exerted by some garments appears slight-for example, garment $d$, fig 1-the control of distension achieved can be worth while (fig 3). These are important considerations in the current debate regarding the relative merits of support garments of different constructions, and they seem to justify extension of the assessment procedure beyond measurement of compression to studies of the control of the distension of veins themselves.

It is a pleasure to acknowledge our thanks to Professor $\mathrm{H}$ Fessler, Professor A D M Greenfield, Mr O J Kingdon, and Mr G S Makin for their encouragement and advice.

This work was supported by a grant from Elbeo Limited.

\section{References}

1 Somerville, J J F, and Byrne, P J, British fournal of Surgery, 1973, 60, 908. 2 Research Institute, Hohenstein, West Germany, Report, November 1972.

${ }^{3}$ Meyerowitz, B R, and Crook, A, The Lancet, 1960, 2, 122.

${ }^{4}$ Makin, G S, Mayes, F B, and Holroyd, A M, British fournal of Surgery, 1969, 56, 369.

5 Somerville, J J F, et al, British fournal of Surgery, 1974, 61, 979.

${ }^{6}$ Ashton, H, British Medical fournal, 1966, 2, 1427. 